\title{
Male flies with yellow balls - New observations on the eversible vesicles on the postabdomen of male Thaumatomyia notata (Diptera: Chloropidae)
}

\author{
MARION KOTRBA
}

Zoologische Staatssammlung, Münchhausenstr. 21, 81247 München, Germany; e-mail: marion.kotrba@zsm.mwn.de

Key words. Diptera, Chloropidae, Thaumatomyia, aggregation, pheromone, glands, histology

\begin{abstract}
The paired eversible vesicles on the postabdomen of male T. notata are likely to play an important role in intraspecific communication and possibly in the notorious aggregation behaviour of these flies at buildings in autumn. The morphological and histological study of these organs provides new evidence supporting the hypothesis that they are pheromone glands. They also constitute a strong optical signal. A detailed survey of these structures could provide the bases for targeted control methods.
\end{abstract}

\section{INTRODUCTION}

The yellow swarming fly Thaumatomyia notata (Meigen, 1830) (Fig. 1) is notorious for its mass occurrences in Germany and neighbouring countries (Nartshuk, 2000; Kotrba, in press a, b), with swarms reaching several tens of millions of flies invading the upper floors of certain buildings in autumn in search of hibernation sites. Although mostly harmless, they constitute a considerable nuisance to the inhabitants. The frequency of these mass occurrences has increased markedly in the last decade, making the development of targeted control measures ever more urgent.

Nartshuk (2000) described paired eversible vesicles on the postabdomen of male $T$. notata and proposed that a pheromone produced by specific glands within these vesicles attracts females during reproduction and both sexes before hibernation. If the mass aggregations of $T$. notata in autumn are due to pheromonal attraction, this would provide options for their targeted control, e.g. by using pheromone baited traps. Therefore, a detailed study of the eversible vesicles and their supposed role in the production or release of aggregation pheromones appears reasonable.

In this paper the morphology and histology of the vesicles and the respective display behaviour of the flies are described and discussed.

\section{MATERIAL AND METHODS}

Live specimens of $T$. notata were collected from an infested building (hibernation site) in Murnau, Bavaria, Germany in April 2006 and September 2006. The flies were subsequently kept and observed in the laboratory under natural light conditions and room temperature in clear plastic cages with moist tissue flooring and dishes containing brewer's yeast and honey.

The eversible vesicles of freshly killed males were artificially everted by gentle lateral squeezing of the abdomen using fine forceps under a stereomicroscope. Photographs were taken using a Leitz MZ 8 stereomicroscope equipped with a Zeiss AxioCam digital camera. When the vesicles were fully everted, the posterior half of the abdomen was severed from the rest of the body, submerged in Bouin's fixative for several hours and then rinsed in $70 \%$ ethanol for several days. For histology the fixed abdomens were embedded using a standard procedure in Durcupan ACM (Fluka). Semi-thin sections $(2 \mu \mathrm{m})$ were cut with a glass knife, stained according to Richardson (1960) and observed under a Zeiss Axioskop 2 compound microscope equipped with a Zeiss AxioCam digital camera. For SEM the fixed abdomens were dehydrated, gold coated and observed with a Zeiss Leo1430VP scanning electron microscope.

\section{RESULTS}

\section{Morphology}

The vesicles are paired membranous pouches, positioned laterally in the pleural area between segment 5 and the hypopygium of the male postabdomen (Figs 2, 3, 5, 6 ). Normally they are more or less concealed inside the body. When everted, they are easily seen with the naked eye as small, roundish, brightly yellow grains at the apex of the abdomen, superficially resembling orchid pollinia.

Under the stereomicroscope the vesicles appear oval with a dorsoventral furrow along the middle. Their colour reflects the bright yellow colour of the testes that are visible through the translucent ventral body wall (Figs 2, 3). No corresponding structures were detected on the female postabdomen (Fig. 4).

Scanning electron microscopy reveals that, unlike the adjacent membranous areas, which are either covered with microtrichia or smooth (midventrally), the surface of the vesicles is finely wrinkled and ornamented by numerous small folds, which bear small spinules (Fig. 7). There are no apparent pores.

\section{Histology}

A cross section through the postabdomen reveals that the eversible vesicles are lined internally by a thick layer of tissue that can be roughly divided into a spongy apical layer consisting of cells with large vacuoles and a dense basal layer of large columnar cells. Muscles are attached to the cuticle below the furrow in the middle of the vesicles (arrows in Fig. 8). From there they draw inwards dorsomedially, obviously serving to retract the vesicles, 

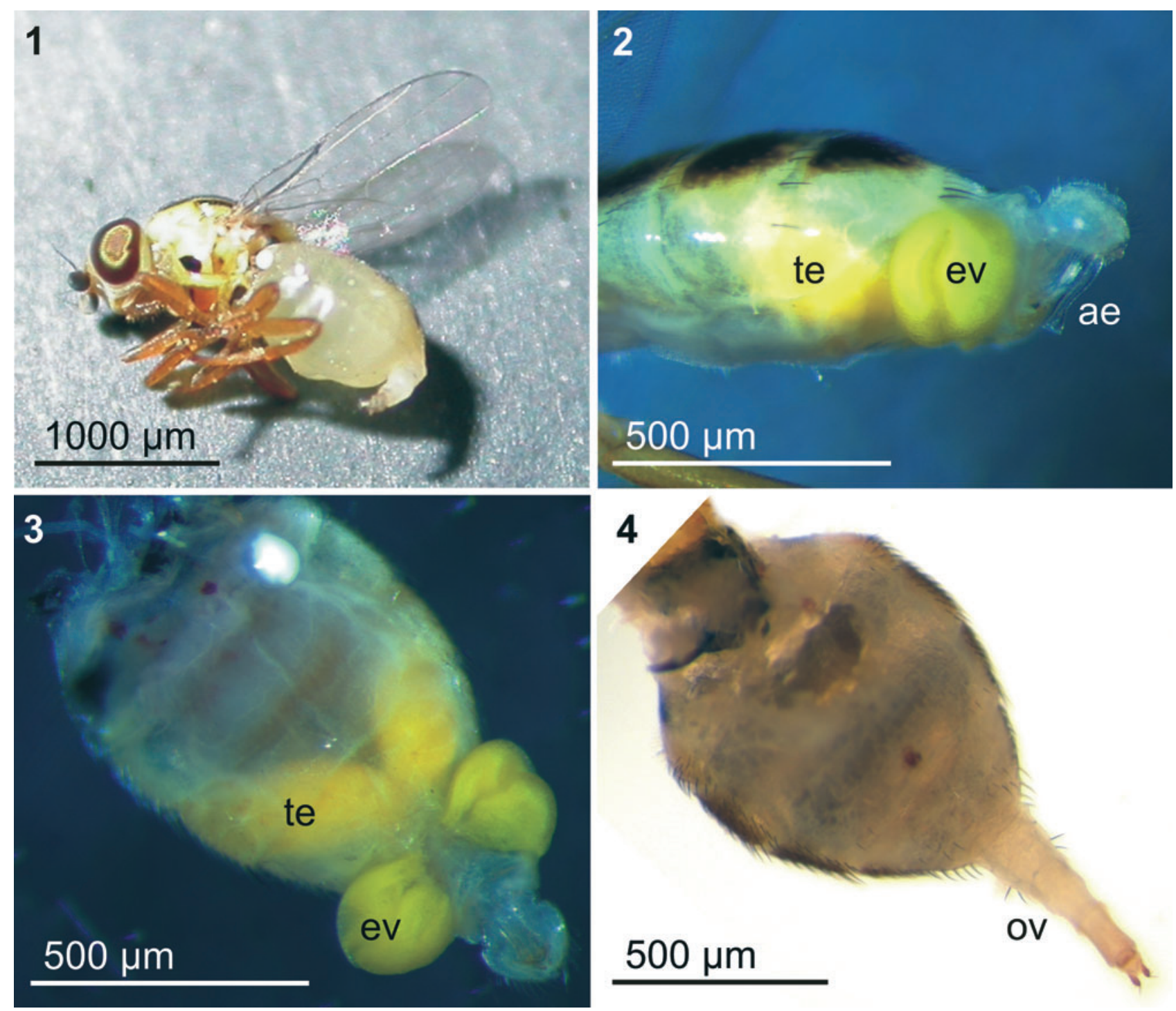

Figs 1-4. Thaumatomyia notata, stereomicroscope photographs. 1 - female; 2 - 3 male abdomen with vesicles everted; 2 - lateral view; 3 - ventral view; 4 - female abdomen ventral view. ae - aedeagus; ev - eversible vesicle; ov - ovipositor; te - testis.

while their eversion is probably achieved via body pressure.

At higher magnification the layered organisation of the eversible vesicles becomes more obvious (Fig. 9). The cuticle (I) is comparatively thin and flexible. Its surface is ornamented by numerous deep clefts and folds. There are no apparent pores. Unlike the adjacent areas of the pleural region, where the cuticle is lined by a flat, apparently single layered epithelium, the tissue lining the eversible vesicles is thick and histologically differentiated into distinct layers. The apical cell layer (II) consists of mediumsized cells with small irregular nuclei (about $3 \mu \mathrm{m}$ in diameter), which are located predominantly in the basal half of the cells. This layer appears spongy due to numerous large and apparently empty vacuoles. It could not be determined, whether these vacuoles are intra- or extracellular and what their contents in vivo might be. The cells of the basal layer (III) are much larger, columnar, and arranged in a regular single layer. Towards the body cavity they are lined by a distinct basement mem- brane (IV). The comparatively large and round nuclei (about $6 \mu \mathrm{m}$ in diameter) are located near the basal third of the cells (IIIc). The cytoplasm between the nuclei and the basal lamina is dense and homogenous (IIId). Between the nuclei and the apical seam, the cytoplasm is more heterogenous (IIIb), with dense, plaque-like areas beside apparently empty ones, mainly in the apical third. Near the apical cell border the cytoplasm forms a narrow dense and homogenous seam (IIIa). There are no apparent intracellular canals or excretory ducts. The columnar cells of layer III resemble class 1 gland cells as defined by Noirot \& Quennedy (1974), with the exception that they are not in direct contact with the overlying cuticle but covered by the apical cell layer (II). As far as can be judged from light microscopy, these cells are highly likely to be secretory.

\section{Display behaviour}

Flies with everted vesicles were observed in the spring at the infested buildings. Males collected at the hiberna- 

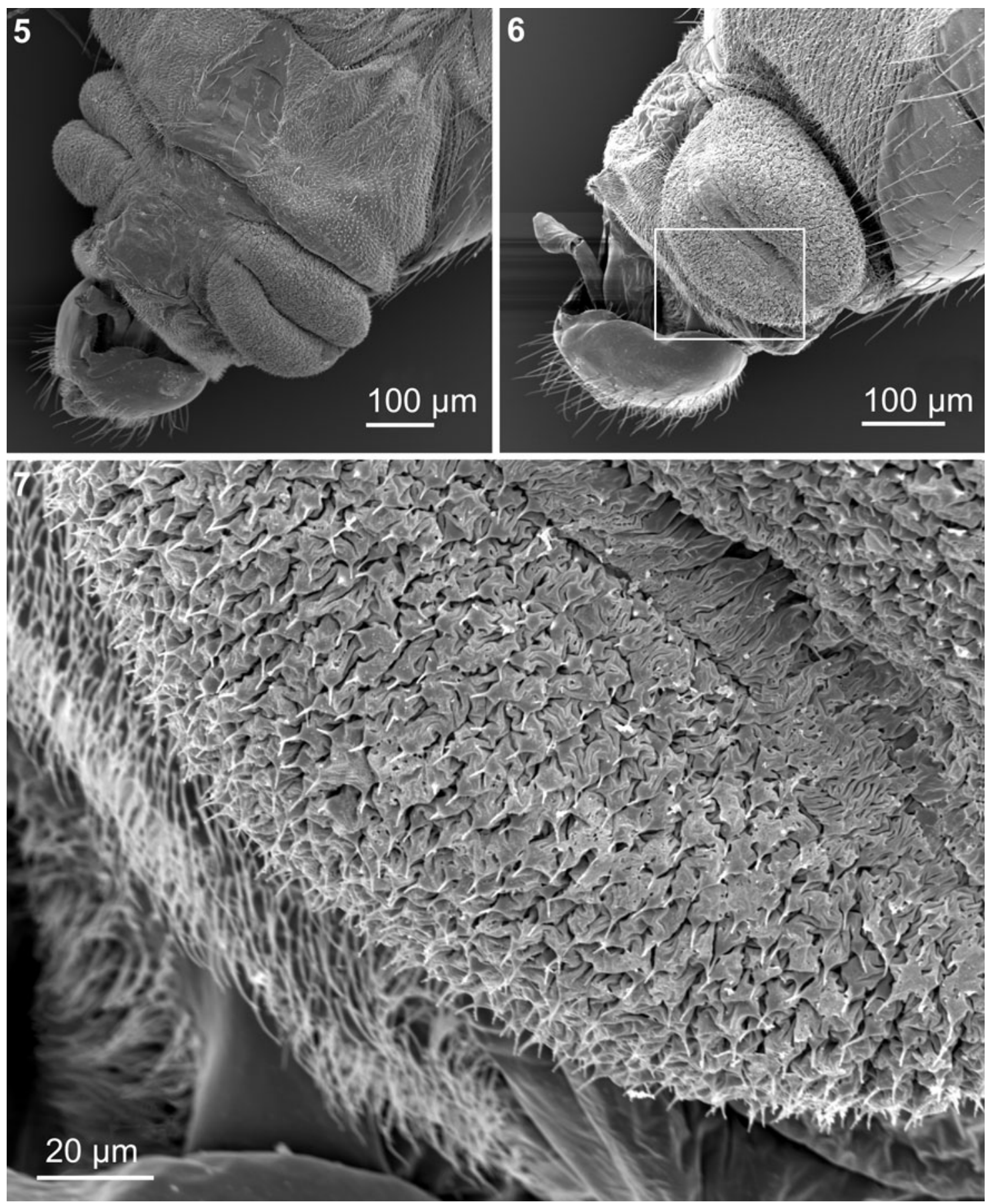

Figs 5-7. Thaumatomyia notata, SEM photographs, male postabdomen with vesicles everted. 5 - ventral view; 6 - lateral view; 7 - surface of eversibe vesicle enlarged from Fig. 6.

tion site in April 2006 were regularly observed to evert their abdominal vesicles, especially in the afternoon when there was bright sunshine. The bright yellow vesicles remained everted for long periods of time while the process of eversion or retraction per se took less than one second. Often the eversion of the vesicles seemed to happen in direct response to an approaching conspecific. When conspecifics walked or hovered nearby, the tip of the abdomen with the everted, brightly yellow vesicles was twisted in their direction and both wings were vibrated in short bouts of about $1 / 2$ second duration about once a second for several seconds.

Eversion of the abdominal vesicles was not observed at hibernation sites in autumn or shown by the flies collected and observed in the laboratory in late September 2006.

\section{DISCUSSION}

Pairs of eversible pouches on the male postabdomen are present not only in Thaumatomyia notata, but also in $T$. flavifrons (Macquart, 1835) and T. sulcifrons (Becker, 

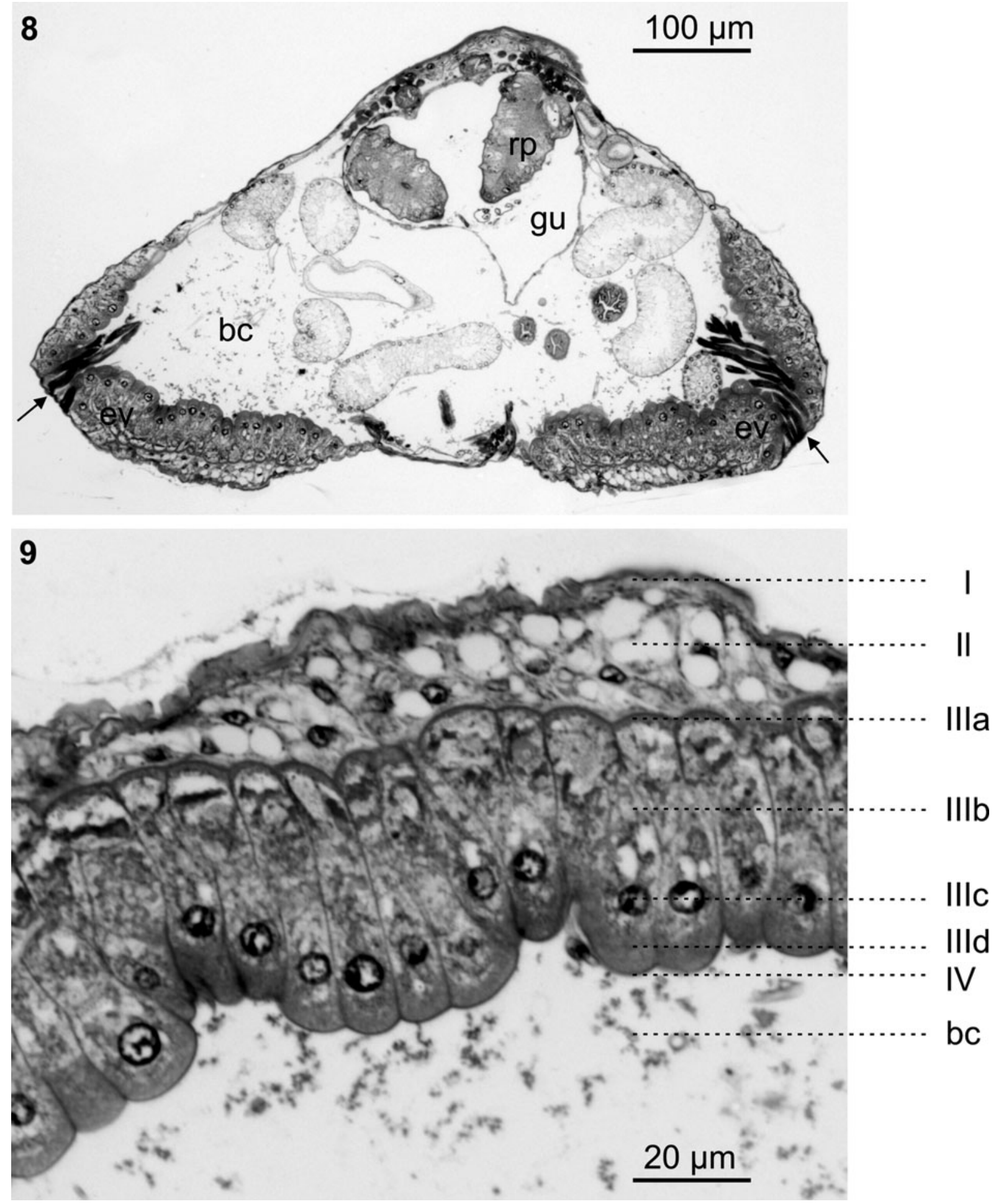

Figs 8-9. Thaumatomyia notata, semi-thin sections. 8 - cross section through the male postabdomen with vesicles everted; 9 enlarged cross section through eversible vesicle wall. bc - body cavity; ev - eversible vesicle; gu - gut; rp - rectal papilla; arrows muscle insertions; I - cuticle; II - spongy apical cell layer; III - basal layer of columnar cells; III a - dense apical seam; III b - heterogenous cytoplasm; III c - nuclei; III d - dense basal seam; IV - basement membrane.

1907), as well as in T. glabra (Meigen, 1830), where they are confluent dorsally (Andersson, 1977; Nartshuk, 2000). Males of Merochlorops lucens (de Meijere, 1908), also a member of the Thaumatomyia genus group within the Chloropinae, have 3 pairs of smaller eversible pouches in the same area (Andersson, 1977). This feature might therefore constitute a common character for the entire genus Thaumatomyia (Andersson, 1977), if not an even larger clade. Similar eversible abdominal structures in some Oscinellinae genera such as Polyodaspis Duda, 1933, Lasiambia Sabrosky, 1941 and Chaetochlorops Malloch, 1914 (Andersson, 1977; Ismay \& Nartshuk, 
2000; Hibbert \& Wheeler, 2007) most likely evolved independently (Nartshuk 1977).

In none of these taxa has the function of the eversible vesicles been studied, but it has been suggested that they are involved in the production and dispersal of pheromones (Andersson, 1977; Nartshuk, 2000), as are similar structures in some Tephritidae (e.g. Feron, 1959; Prichard, 1967; Fletcher, 1969; Nation, 1974, 1981). That $T$. notata produces an aggregation pheromone has long been proposed by various authors to account for its recurring aggregations at certain buildings year after year (Zürcher, 1924; Rozsypal, 1930; Weidner, 1990; Nartshuk, 2000; Tschirnhaus, pers. com.).

Nartshuk (2000) proposed that the pheromone produced by the eversible vesicles attracts females during reproduction and both sexes before hibernation. So far, the eversion of the vesicles was observed only in spring and summer, i. e. in the premating or mating period (see also Steyskal, 1945), but not in autumn. This suggests that they are primarily utilized in the context of mate finding. The same is probably true of the other species of Thaumatomyia that possess similar structures but do not form mass aggregations at buildings (Duda, 1933; Nartshuk, 2000). However, it is possible that pheromones released at the aggregation site in spring persist over the year and still suffice to attract the next generation to hibernate there in autumn.

Some circumstantial evidence corroborates the hypothesis that the vesicles are involved in the production and dispersal of pheromones: (1) The raising of the abdomen with everted yellow vesicles and the simultaneous vibrating of the wings seems apt for pheromone dispersal. (2) The histologically distinct epithelium with a regular layer of large columnar cells with large basal nuclei suggests a glandular function. A similar columnar cell layer was described for the pheromone producing pleural glands of male Tephritidae, although they lack an apical cell layer (Prichard, 1967; Nation, 1974, 1981). (3) The ornamentation of the cuticular surface with folds and spinules, which likewise is reminiscent of the pleural glands in Tephritidae, increases the surface area over which a pheromone might be dispensed and volatilized (Nation, 1981). (4) A jar full of dead and dried T. notata collected at an infested building still emitted a very strong and pleasant scent of sweet almonds and honey after three years, each time it was freshly opened. This odour could be a pheromone. However, in preliminary tests, freshly collected dead flies did not attract additional conspecifics in autumn.

Some of the described morphological and histological properties of the eversible vesicles could also indicate additional or alternative functions. Although licking or extensive palpating of the everted vesicles was not observed, it is possible that their supposed secretion provides a gustatory stimulus and/or that the surface ornamentation provides tactile stimuli during close range interactions (e.g. at the hibernation site). Most importantly, the brightly yellow structures, which are visible to the naked eye, inevitably provide an optical signal for conspecifics.

Bright yellow is known to be attractive to many insects and yellow sticky traps are attractive also to T. notata (B. \& S. Schlick, pers. comm.). In T. notata this could be explained in three ways: (1) After hibernation the females do not have mature oocytes and probably need a high protein diet to reach fertility. $T$. notata specimens feed avidly on the yellow blossoms of daisies (Bellis perennis Linné, 1753) and dandelions (Taraxacum officinale spec.) in spring. The small, round, bright yellow vesicles could attract females by mimicking pollen sacks or grains. (2) The colour of the vesicles is the same as that of the testes, which are larger in spring and summer than in autumn. The vesicles could mimic particularly large testes as an indicator of maturity and/or high fertility. Similarly, in Rhamphomyia longicauda Loew, 1861 (Empididae) females inflate expandable pouches on the pleural margins of the abdomen to mimic the presence of mature eggs (Funk \& Tallamy, 2000). (3) In some animal taxa bright yellow colour signals the ample presence of carotenoids and health. It has been proposed that carotenoids are used in ornamental traits because, given their physiological and chemical properties, they can be used as honest indicators of individual health, and hence they can be used by animals when selecting potential mates (e.g. McGraw \& Hill, 2000a, b; Saks et al., 2003). All these interpretations, however, remain speculative for the time being.

\section{CONCLUSIONS}

The results of the present study support the hypothesis that the eversible vesicles of $T$. notata play an important role in the intraspecific communication of these flies and are possibly involved in their notorious aggregation behaviour. Evidence that they are pheromone producing glands is growing but still only circumstantial. For a conclusive interpretation, the chemical contents of these structures need to be identified and tested for their attractiveness to T. notata. If a pheromone system is detected, it could lead to the development of specific control measures, such as pheromone traps or the specific removal or destruction of pheromones persisting at the aggregation sites.

This topic is a promising research field and should be pursued in the future.

ACKNOWLEDGEMENTS. This project was part of a study of Thaumatomyia notata financially supported by the Association of Bavarian Savings Banks. I thank E. Lodde for preparing the histological sections and B. Stock for SEM preparation and SEM photography. D. Burckhardt, E. Nartshuk and two anonymous reviewers contributed helpful comments on a previous draft of the manuscript.

\section{REFERENCES}

Andersson H. 1977: Taxonomic and phylogenetic studies on Chloropidae (Diptera) with special reference to Old World genera. Entomol. Scand. (Suppl.) 8: 200 pp. 
DudA O. 1933: 61. Chloropidae. In Lindner E. (ed.): Die Fliegen der palaearktischen Region 6(1). Schweizerbart, Stuttgart, pp. 1-248 + plates i-iii.

Feron M.M. 1959: Attraction chimique du mâle de Ceratitis capitata Wied. (Dipt.: Tephritidae) pour la femelle. C.R. Acad. Sci. Paris 248: 2403-2404.

FLETCHER B.S. 1969: The structure and function of the sex pheromone glands of the male Queensland fruit fly, Dacus tryoni. J. Insect Physiol. 15: 1309-1322.

FunK D.H. \& TAllamy D.W. 2000: Courtship role reversal and deceptive signals in the long-tailed dance fly, Rhamphomyia longicauda. Anim. Behav. 59: 411-421.

Hibbert A.C. \& Wheeler T.A. 2007: Systematics of Chaetochlorops Malloch, 1914 (Diptera: Chloropidae) and morphology of secondary sexual structures in the male abdomen. Stud. Dipterol. 14: 97-105.

Ismay J.W. \& NARTShuK E.P. 2000: Family Chloropidae. In Papp L. \& Darvas B. (eds): Contributions to a Manual of Palaearctic Diptera with Special Reference to Flies of Economic Importance. Appendix. Science Herald, Budapest, pp. 387-429.

Котвва M. in press a: Massenauftreten der Gemeinen Rasenhalmfliege Thaumatomyia notata (Diptera, Chloropidae) an Gebäuden - ein zunehmendes Problem in unserer Zeit? In Aspöck H. (ed.): Krank durch Arthropoden. Denisia.

Kotrba M. in press b: Massenauftreten der Gemeinen Rasenhalmfliege Thaumatomyia notata (Diptera, Chloropidae) an Gebäuden: Determination - Biologie - Verbreitung. Stud. Dipterol.

McGraw K.J. \& Hill G.E. 2000a: Differential effects of endoparasitism on the expression of carotenoid- and melaninbased ornamental coloration. Proc. R. Soc. Lond. (B) 267: $1525-1531$.

McGraw K.J. \& Hill G.E. 2000b: Carotenoid-based ornamentation and status signalling in the house finch. Behav. Ecol. 11: $520-527$.
NARTSHUK E.P. 1977: Comparative morphological research of abdomen and genital structures in Chloropidae (Diptera). Trudy Vses. Entomol. Obshch. 58: 87-118.

NARTSHUK E.P. 2000: Periodicity of outbreaks of predatory fly Thaumatomyia notata Mg. (Diptera, Chloropidae) and its possible reasons. Entomol. Rev. 80: 911-918.

Nation J.L. 1974: The structure and development of two sex specific glands in male caribbean fruit flies. Ann. Entomol. Soc. Am. 67: 731-734.

NAtion J.L. 1981: Sex specific glands in tephritid fruit flies of the genera Anastrepha, Ceratitis, Dacus and Rhagoletis (Diptera: Tephritidae). Int. J. Insect Morphol. Embryol 10: 121-129.

Pritchard G. 1967: Laboratory observations on the mating behaviour of the island fruit fly Rioxa pornia (Diptera: Tephritidae). J. Aust. Entomol. Soc. 6: 127-132.

RichaRdSON K.C., JARRET L. \& FinKE E.H. 1960: Embedding in epoxy resins for ultrathin sectioning in eletron microscopy. Stain Technol. 35: 313-323.

RozsyPal J. 1930: Ein Beitrag zur Vergesellschaftung und Überwinterungsmöglichkeit der Imagines bei Chloropiden. $Z$. Wiss. InsektBiol. 25: 1-13.

SaKs L., Ots I. \& Horak P. 2003: Carotenoid-based plumage coloration of male greenfinches reflects health and immunocompetence. Oecologia 134: 301-307.

SteYsKal G. 1945: Behavior of Thaumatomyia (= Chloropisca) species (Diptera, Chloropidae). Bull. Brook. Entomol. Soc. 40: 48.

WeIDNER H. 1990: Bemerkungen zum Thema Halmfliege. Prakt. SchädBekämpf. 43(12): 190-191.

ZÜRCHER L. 1924: Beobachtungen über Chloropisca notata. Schweiz. Entomol. Anz. 3(4): 25-28.

Received August 27, 2008; revised and accepted October 8, 2008 